\title{
Absorption of L-Methionine
}

\section{from the Human Small Intestine}

\author{
Harold P. Schedl, Charles E. Pierce, Alan Ruder, and \\ James A. Clufton, with the technical assistance of \\ GeORGE NoKES \\ From the Gastroenterology Research Laboratory, Department of Internal \\ Medicine, State University of Iowa College of Medicine, \\ Iowa City, Iowa
}

\begin{abstract}
A в S T R A C T Absorption of L-methionine was measured in all parts of the human small intestine using transintestinal intubation and perfusion. In four normal subjects, adsorption was higher in the proximal than in the distal intestine. In two patients with nontropical sprue in relapse, there was a proximal zone of low absorption with higher absorption distally. In all parts of the small intestine, absorption showed rate-limiting kinetics as methionine concentration was increased. In normal subjects, the proximal $K_{m}$ (Michaelis constant) was more than 3 times higher than the distal, which suggests a difference in transport mechanisms between the two segments.
\end{abstract}

\section{INTRODUCTION}

Several specific mechanisms have been implicated in the uptake of amino acids by cells (1-3) as well as by the intestinal mucosa $(4,5)$. Despite extensive studies of amino acid transport in a variety of preparations, information on amino acid absorption by the human small intestine is limited (6-10). We studied the pattern of L-methionine absorption in the human small intestine and found differences in transport characteristics between the proximal and distal segments.

This work was presented in part at the Thirty-sixth Annual Meeting of the Central Society for Clinical Research, Chicago, Ill., November 1963.

Received for publication 6 July 1967 and in revised form 27 July 1967.

\section{METHODS}

Subjects. Two normal men (M. R., age 44, and R. L., age 37 ) were volunteers, and the third (H. E., age 62 ) was an ambulatory patient with generalized atherosclerosis. The woman control (B. J., age 44) was a volunteer. The two patients with adult celiac disease were a $62 \mathrm{yr}$ old man, G. H., and a $60 \mathrm{yr}$ old woman, G. L. The diagnosis was made on the basis of the clinical picture, abnormal routine absorption tests, the characteristic changes in the small intestinal mucosa, and the response to a gluten-free diet. The disease was in relapse in both patients, and both were eating gluten-free diets during the period of study. All subjects were hospitalized.

Technique. Absorption was studied by transintestinal intubation (11) using a polyvinyl tubing (Pharmaseal Laboratories, Glendale, Calif.) and a steady-state perfusion technique $(12,13)$. Subjects fasted overnight and were studied in the recumbent position at the same time each morning. Solutions were pumped into the nasal end of the tubing at $15 \mathrm{ml} / \mathrm{min}$ using a constant infusion pump (Bowman pump, Process \& Instruments Co., Brooklyn, N. Y.) The solutions entered the gut through a hole in the side of the tubing above a solid connector. Perfusate was sampled through a similar holc, $15 \mathrm{~cm}$ distal to the entry site and below the solid connector, by siphonage from the anal end of the tube. Perfusion sites were in the small intestine and were designated by distance in centimeters of the proximal hole from the nares. Three solutions, containing different concentrations of L-methionine, were perfused during each run. Usually the solution with the lowest concentration was perfused first, and the one with the highest last. The order of perfusion was reversed without apparent effect on absorption rate in about one-fifth of the runs. After an initial $30 \mathrm{~min}$ wash, three to four successive samples were collected over 4-10-min periods, depending on sample collection rate. Sample volume (usually more than $20 \mathrm{ml}$ ), collection time, and $\mathrm{pH}$ were measured. A 30-40 min wash pe- 


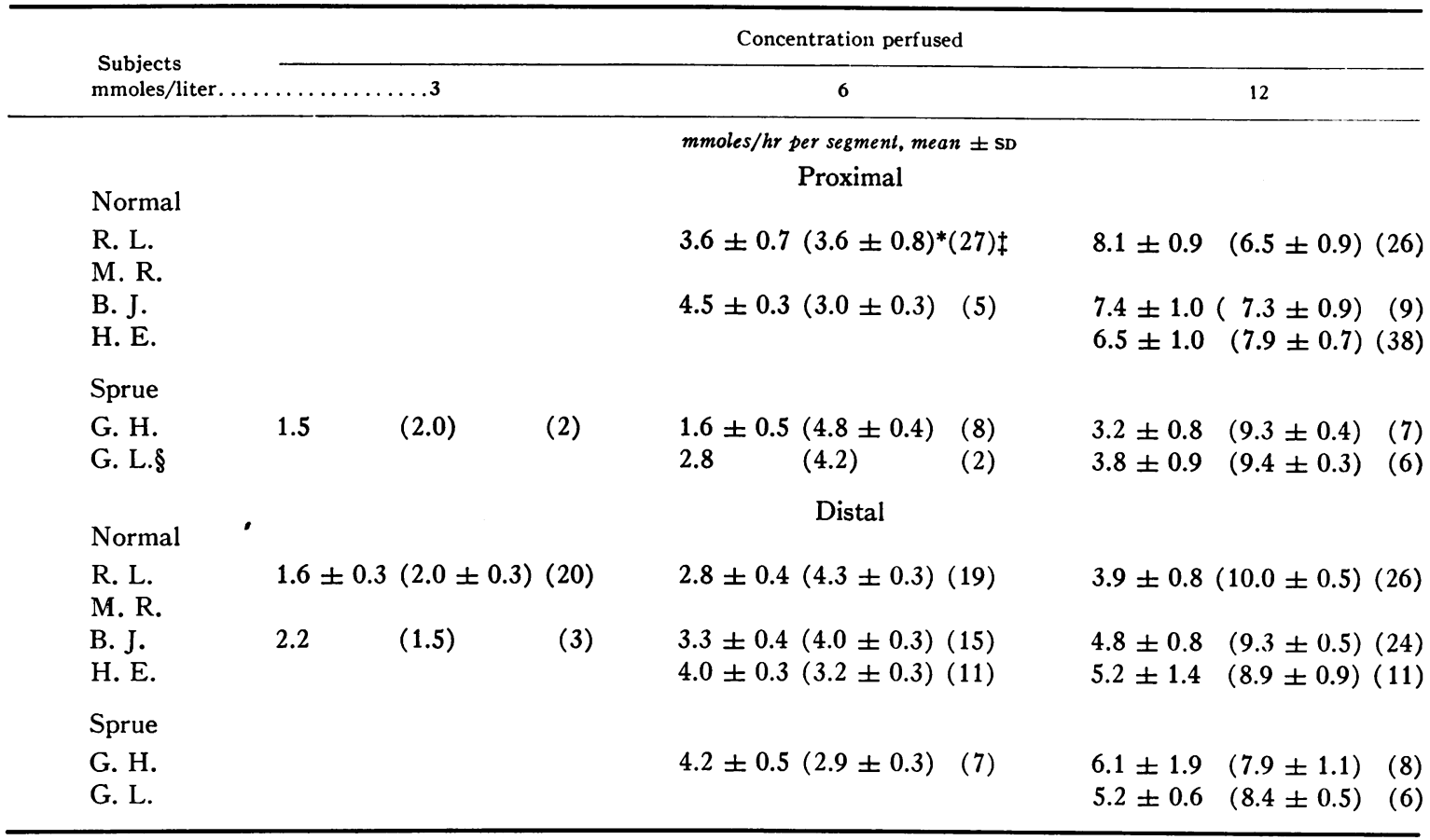

* Geometric mean concentration.

$\ddagger$ Number of samples.

$\$$ Proximal samples are from low rate proximal zone, distal are from the high rate zone (Fig. 2).

riod preceded sample collection from each succeeding solution.

Solutions. L-methionine (N.R.C., A Grade, Calbiochem, Los Angeles, Calif.) solutions in a modified Ringer's $[\mathrm{pH}=7.0 \pm 0.2$ (14)] were maintained isotonic by reducing sodium chloride concentration 0.5 mmole/liter for each mmole of L-methionine per liter. All solutions contained polyethylene glycol (PEG) (Carbowax 4000, Carbide and Carbon Chemicals Co., New York) at a concentration of $1 \mathrm{mg} / \mathrm{ml}$. Phenol red $(5-25 \mathrm{mg} / \mathrm{liter}$, depending on methionine concentration) was added to the second solution to check completeness of wash, i.e., absence of first solution from second, and second solution from third.

Analysis. Methionine was analyzed by a modification of the method of Horn et al. (15). The standard curve, read at $520 \mathrm{~m} \mu$ in the Beckman DU spectrophotometer, was linear to above $2.4 \mathrm{mg}$ of methionine. Sample aliquots approximating $2 \mathrm{mg}$ of methionine in the perfusion solution were analyzed in duplicate. Sample banks containing all components except nitroprusside were run with the samples. Application of the three wave length corrections (16) to readings of samples and standards at 480,520 , and $560 \mathrm{~m} \mu$ gave essentially the same results as reading at $520 \mathrm{~m} \mu$ only. No methionine was found on analysis of perfusates from solutions lacking methionine.

PEG was analyzed turbidimetrically by a modification of the method of Hydén (17). The ratio of initial to final PEG concentrations (PEG ratio) was used to correct for net water movement. L-methionine absorption was calculated as follows :

(a) Per cent unabsorbed $=$ $100 \frac{\text { (final L-methionine concn) }}{\text { (initial L-methionine concn) }} \times($ PEG ratio) ;

(b) Percent absorbed $=100-$ Per cent unabsorbed;

(c) Absorption, mmoles/hr per gut segment = (Per cent absorbed) 100

$\times$ (Initial L-methionine concn, mmoles/liter) $\times$ (Pump rate, liters $/ \mathrm{hr})$;

(d) Geometric mean concn $=$

$$
\sqrt{\text { (initial concn) (final concn). }}
$$

Data were plotted as described by Lineweaver and Burk (18), and $K_{m}$ and $V_{\max }$ were obtained from the slopes and intercepts of lines fitted by the method of least squares.

\section{RESULTS}

The pattern of small intestinal methionine absorption is shown in Fig. 1 for normal subjects and in Fig. 2 for patients with nontropical sprue. These absorption data are combined to compare proximal 
TABLE I-(Continued)

in Proximal and Distal Small Intestine

\begin{tabular}{|c|c|c|}
\hline \multicolumn{3}{|c|}{ Concentration perfused } \\
\hline 25 & 50 & 100 \\
\hline \multicolumn{3}{|c|}{ mmoles $/ h r$ per segment, mean \pm SD } \\
\hline $\begin{array}{r}11.2 \pm 2.2(19.0 \pm 1.6)(31) \\
13.0 \pm 1.4(17.7 \pm 1.2)(11) \\
14.3 \pm 3.0(16.6 \pm 2.2)(12) \\
9.4 \pm 2.2(19.9 \pm 1.8)(41)\end{array}$ & $\begin{array}{l}20.2 \pm 3.7(40.0 \pm 2.8)(15) \\
16.5 \pm 3.1(42.6 \pm 1.2)(8) \\
21.0 \pm 5.9(40.0 \pm 2.7)(7) \\
13.2 \pm 2.9(44.4 \pm 1.9)(25)\end{array}$ & $\begin{array}{l}21.4 \pm 5.7(86.9 \pm 3.6)(5) \\
27.2 \pm 5.4(85.7 \pm 6.2)(12)\end{array}$ \\
\hline $\begin{array}{l}4.6 \pm 2.1(20.7 \pm 1.3)(12) \\
5.0 \pm 0.7(21.8 \pm 0.3)\end{array}$ & $\begin{array}{l}8.3 \pm 2.1(41.7 \pm 2.7)(9) \\
6.0 \pm 3.3(42.7 \pm 3.9)(12)\end{array}$ & $\begin{array}{l}6.4 \pm 2.0(92.6 \pm 3.8) \\
8.1 \pm 5.0(89.8 \pm 5.1)\end{array}$ \\
\hline \multicolumn{3}{|c|}{ Distal } \\
\hline $\begin{array}{l}4.1 \pm 0.9(23.5 \pm 0.6)(40) \\
5.3 \pm 0.8(22.4 \pm 0.6)(12) \\
5.8 \pm 1.3(22.1 \pm 1.1)(28) \\
6.0 \pm 1.4(21.7 \pm 0.9)(15)\end{array}$ & $\begin{array}{r}7.8 \pm 2.8(47.2 \pm 1.7)(31) \\
8.0 \pm 1.7(47.3 \pm 1.0)(15) \\
10.0 \pm 4.0(45.9 \pm 3.2)(13) \\
6.2 \pm 2.8(47.2 \pm 0.9)(14)\end{array}$ & $\begin{array}{r}9.4 \pm 3.3(94.7 \pm 1.9)(18) \\
11.3 \pm 3.6(95.9 \pm 2.0)(13)\end{array}$ \\
\hline $\begin{array}{l}15.2 \pm 1.2(16.7 \pm 1.1)(5) \\
10.1 \pm 4.2(19.1 \pm 3.0)(9)\end{array}$ & $\begin{array}{l}23.0 \pm 4.5(42.1 \pm 4.0)(8) \\
16.8 \pm 6.7(43.8 \pm 5.2)(28)\end{array}$ & $\begin{array}{l}24.7 \pm 13.9(87.9 \pm 5.8) \\
21.5 \pm 7.1(85.0 \pm 8.5)(19)\end{array}$ \\
\hline
\end{tabular}

and distal rates in relation to geometric mean concentration in Table I. To show the effect of concentration on absorption, data from three stbjects in Table $I$ are plotted in relation to geometric mean concentrations in Figs. 3-5. Examples of the fit of proximal and clistal data to Lineweaverliurk plots (reciprocal of rate vs. reciprocal of concentration ) are shown in Figs. 6 and 7. Kinetic clata are summarized in Table II.

\section{DISCUSSION}

In normal subjects, methionine absorption proceeded at a higher rate in the proximal than in the distal small intestine (Fig. 1), especially at higher methionine concentrations. In contrast, patients with sprue had a zone of low absorption proximally (Fig. 2), where mucosal damage was presumably greatest, and a zone of higher absorption distally. The absorption profile of the small intestine showed individual variations in both normal subjects and patients with sprue. The zone of transition from high proximal absorption rates was nearer the nares in B. J. and M. R. than in R. L. H. E. showed only a minimal gradient, with very distal transition. In all subjects, the absorption rate in relation to intraluminal concentration showed rate-limiting kinetics in the proximal and distal small intestine (Table I, Figs. 3-5). The $K_{m}$ and $V_{\max }$ data (Table II, Figs. 6 and 7) showed marked differences between the proximal and distal small intestine. In normal subjects, the proximal $K_{m}$ values ranged from 12 to 28 and the distal from 2.0 to 5.7, depending on concentration range used for calculation. In accord with the high proximal and low distal methionine absorption rates, the proximal $V_{\max }(16-33$ mmoles/hr per segment) was much higher than the distal (5-6 mmoles/hr per segment).

In obtaining $K_{m}$ and $V_{\max }$, it is essential that absorption rates be measured at concentrations that define the rate curve, i.e., both below and above $K_{m}$. The number of higher concentrations from the flat portion of the curve that are used must be limited, otherwise bias is introduced. 


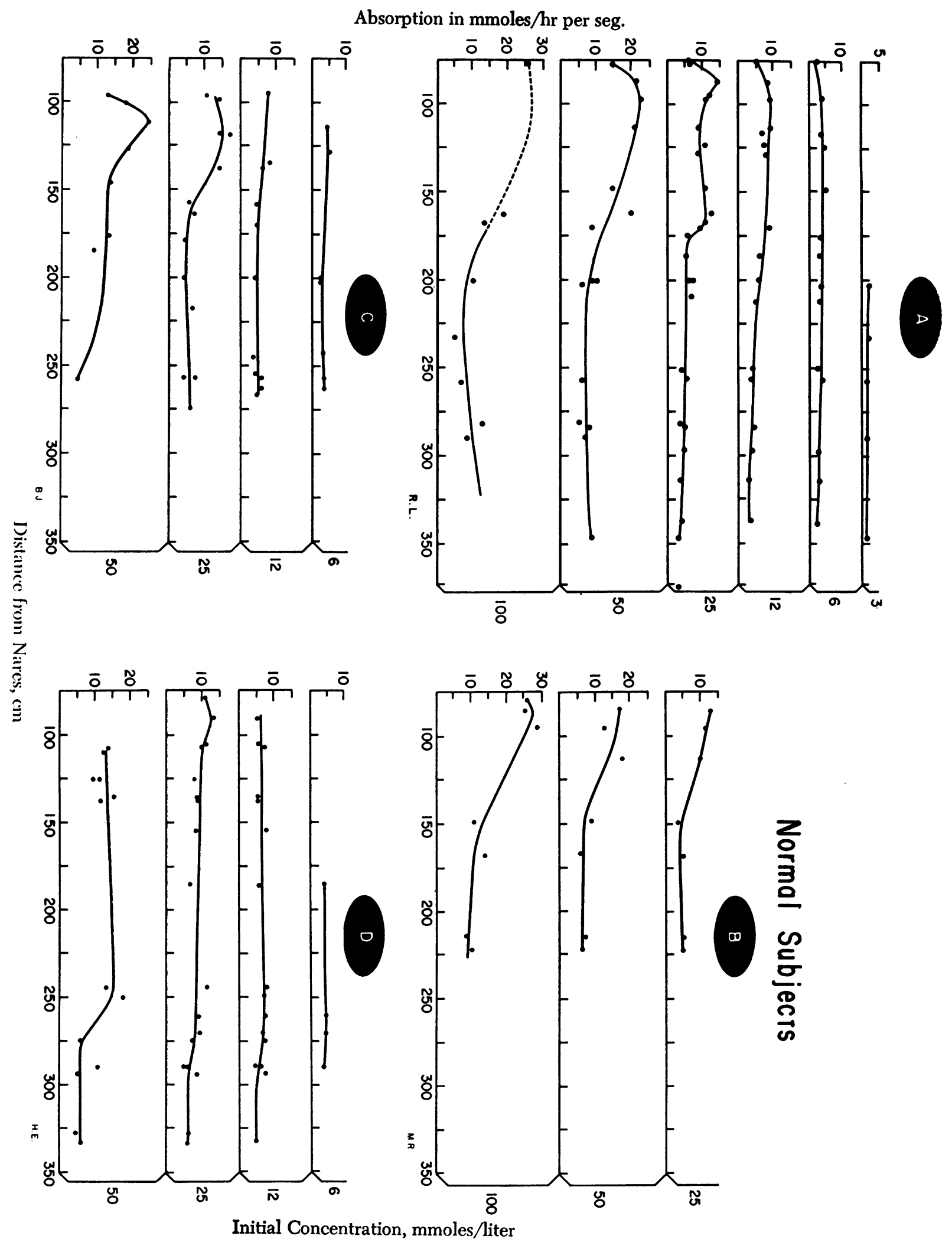




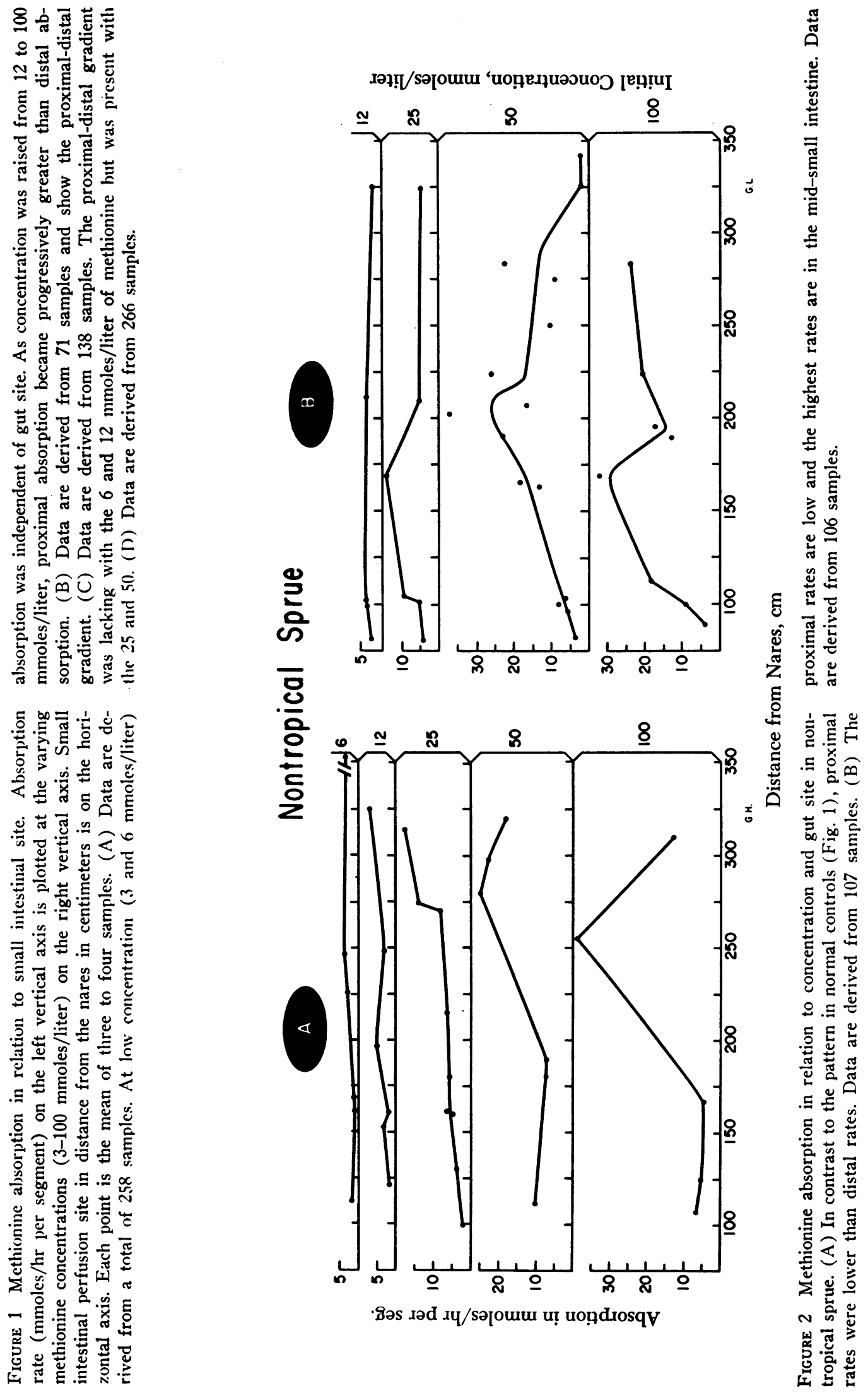


TABLE II

Kinetic Constants for L-Methionine Absorption

\begin{tabular}{|c|c|c|c|}
\hline Subjects & $K_{m}$ & $V_{\max }$ & Concn range* \\
\hline & $\begin{array}{c}\text { mmoles/ } \\
\text { liter }\end{array}$ & $\begin{array}{l}\text { mmoles/hr } \\
\text { per segment }\end{array}$ & $\begin{array}{c}\text { mmoles/ } \\
\text { liter }\end{array}$ \\
\hline \multicolumn{4}{|c|}{ Proximal } \\
\hline Normal & & & \\
\hline R. L. & 27.6 & 32.8 & $6-100$ \\
\hline M. R. & 24.5 & 30.1 & $25-100$ \\
\hline B. J. & 13.7 & 24.5 & $6-50$ \\
\hline H. E. & 11.6 & 15.8 & $12-50$ \\
\hline \multicolumn{4}{|l|}{ Sprue } \\
\hline G. H. & 6.1 & 5.6 & $3-100$ \\
\hline G. L. & 7.0 & 7.2 & $6-100$ \\
\hline \multicolumn{4}{|c|}{ Distal } \\
\hline \multirow{3}{*}{ R. I. } & & & \\
\hline & 5.7 & 6.3 & $3-50$ \\
\hline & $\begin{array}{l}4.4 \\
2.8\end{array}$ & 5.4 & $\begin{array}{l}3-25 \\
6-25\end{array}$ \\
\hline \multirow{2}{*}{ B. J. } & $\begin{array}{l}2.0 \\
2.9\end{array}$ & $\begin{array}{l}4.1 \\
6.4\end{array}$ & $3-50$ \\
\hline & 2.6 & 5.9 & $3-25$ \\
\hline H. E. & 2.0 & 6.4 & $6-50$ \\
\hline \multicolumn{4}{|l|}{ Sprue } \\
\hline G. H. & 15.4 & 24.7 & $6-100$ \\
\hline G. L. & 48.3 & 34.9 & $12-100$ \\
\hline
\end{tabular}

* Absorption rates over this initial concentration range were used for calculating $K_{m}$ and $V_{\max }$ because they appeared to give the best estimate. Inclusion of a wider concentration range did not alter the relative values greatly and appeared to introduce artifact.

Under steady-state conditions, absorption at high concentrations may not be great enough to give reliable rates, because the difference between initial and final concentrations is too small. The converse problem arises at low concentrations when absorption rates are too high. It is difficult to relate rate to a specific concentration, because concentration changes so greatly. For this reason, $K_{m}$ and $V_{\max }$ values at several concentration ranges are given for R. L. and B. J. (Table II, Distal).

The contrasting $K_{m}$ values between the proximal and distal small intestine in normial subjects suggest differences in transport behavior of methionine consistent with differences in carrier function. The transport of methionine (and of neutral amino acids generally) is heterogeneous in the Ehrlich ascites tumor cell (2). The interactions among neutral amino acids for uptake by the cells showed that affinities clustered into two

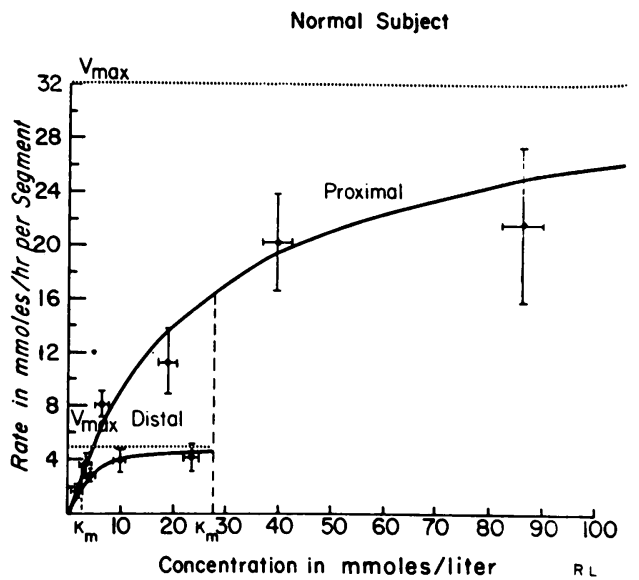

Figure 3 Methionine absorption in relation to concentration in proximal and distal small intestine. Absorption rate (mmoles/hr per segment) on the rertical axis is plotted at the geometric mean of initial and final concentration on the horizontal axis. Means and standard deviations of rates and geometric mean concentrations are indicated. $K_{m}$ (mmoles/liter) is 28 in the proximal and 2.5 in the distal segment, and the respective $F_{\text {max }}$ (mmoles/hr per segment) values are 3.3 and 5 . Curves are fitted from $K_{m}$ and $l_{\text {max }}$.

groups. Methionine had a particularly strong dual affinity and appeared in both the lipophilic and hydrophilic groups, although there was some overlap between all members of both gromps. More recently, methionine uptake by the Ehrlich cell has been divided into sodium-sensitive and sorliuminsensitive components (3). The rat small intestine behaves as if there were a carrier system

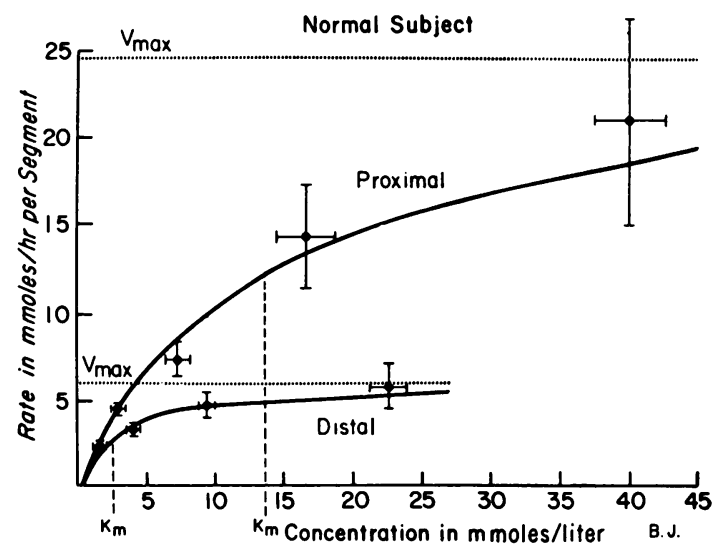

Figure 4 Methionine absorption in relation to geometric mean concentration in proximal and distal small intestine. $K_{m}$ and $V_{\max }$ are, respectively, 14 and 25 in the proximal and 2.6 and 6 in the distal segments. 


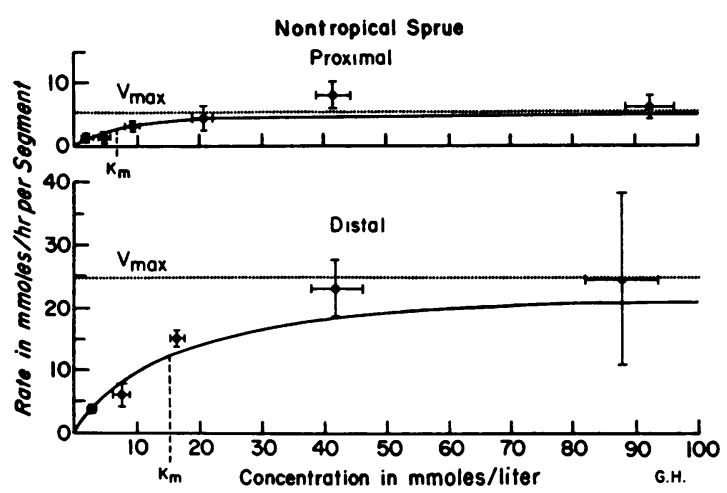

Figure 5 Methionine absorption in relation to geometric mean concentration in proximal and distal small intestine in a patient with nontropical sprue. In contrast to normal controls (Figs. 3 and 4 ), absorption rate, $K_{m}$, and $V_{\max }$ of the distal segments are greater than those of the proximal segments.

common to methionine, glycine, and proline, but with an additional carrier for glycine and proline (5). However, in the rat, either the middle-fifth or the entire small intestine was used, and different segnents were not compared. Thus, our finding of an apparent spatial separation with differences of transport at different loci has not previously been demonstrated.

Although in our studies the functional behavior of the human small intestine is consistent with the operation of two different carriers, we have obtained no information on homogeneity of transport systems at either site. Thus, both hypothetical carriers could be present in different proportions in the two sites, or there could be multiple carriers at each site. It is also possible that the basic amino
Normal Subject

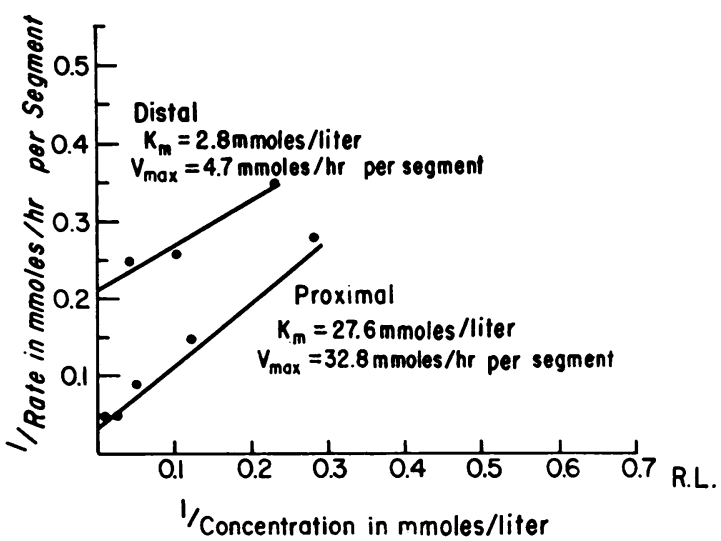

Figure 6 Lineweaver-Burk plot of proximal and distal methionine absorption in a normal subject. The reciprocal of the mean rate is plotted on the vertical axis against the reciprocal of the geometric mean concentration on the horizontal axis. Lines are fitted by the method of least squares.

acid transport system(s) may be involved in methionine transport. In addition, in our studies, as in all others on methionine transport $(4,6-8)$, the intraluminal concentrations of methionine were well above those in blood. Therefore, differences in diffusion permeability between the two segments might explain the differences in transport. The high proximal and low distal $V_{\max }$ values are consistent with the transport rates actually observed at the two sites. Because of the probability that multiple transport processes are involved, the usual relationship of proportionality between $V_{\max }$ and number of carrier sites seen with only one carrier does not apply here.
Normal Subject

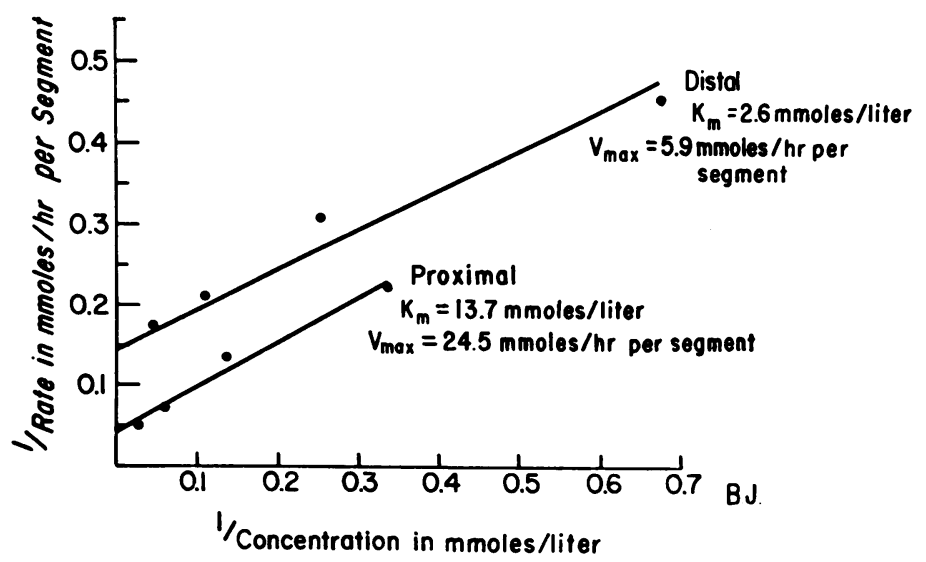

Figure 7 Lineweaver-Burk plot of proximal and distal methionine absorption in a normal subject. 
Functionally, the contrasting transport characteristics defined by $K_{m}$ and $V_{\max }$ can be described as follows. Proximal transport, as shown by the high $K_{m}$, was difficult to saturate and required high concentrations of substrate. It promoted rapid absorption of large amounts of methionine (high $V_{\max }$ ) when supplied at high intraluminal concentrations (high $K_{m}$ ). Distal transport was saturated at much lower concentrations (low $K_{m}$ ) and had a limited capacity (low $V_{\max }$ ). At low concentrations, it would move more methionine per unit time than would the proximal, when both were operating at the same substrate concentration. This proximal-distal kinetic pattern is consistent with optimal small intestinal function. Thus, during feeding, when both exogenous and endogenous (19) amino acids entered the proximal gut at high concentrations, they would be rapidly transported out of the lumen by a downhill process. The absorptive mechanism in the distal gut would remove the low concentrations of amino acid left by the action of the proximal system. Because of the probable reversibility of the transport system for neutral amino acids (20), it is conceivable that the distal mechanism may reabsorb blood amino acids that have leaked into the gut lumen, even though blood amino acid levels are normally quite low.

Determinations of amino acid $K_{m}$ values in the human small intestine published since these studies were completed have been confined to the jejunum. Alanine has a longer lipophilic side chain and had a lower $K_{m}$ (34 and 38 mmoles/liter) than glycine (75 and 77 mmoles/liter) (9). Methionine, with an even longer lipophilic side chain, would be expected to show a still lower $K_{m}$. We found the mean $K_{m}$ for methionine in the proximal small intestine to be about 19 mmoles/liter (Table II). The $K_{m}$ for L-methionine in the entire rat small intestine in vivo was $9.6 \mathrm{mmoles} /$ liter (calculation based on initial concentration) (21). Thus, our distal $K_{m}$ values are lower than reported observations, but this segment was not specifically investigated in the other studies.

The low proximal absorption rates in sprue could be explained by mucosal damage with loss of villi. The decrease in surface area of the perfused segment would be accompanied by a decrease in methionine carrier. The causes for increased distal absorption in sprue are unknown. The sur- face area of the perfused segment is a primary determinant of absorption. If the effective absorbing surface of distal segments in patients with sprue were greater than in normal subjects, other factors being equal, absorption rate would be greater. Motility is decreased in sprue (22). If this decreased motility caused pooling of perfusate and retrograde flow, the perfused segment would be longer than in normal subjects. Thus, in the approximate steady state in sprue, additional surface area would be recruited by retrograde flow, and contact time would be longer than in normal subjects. Since the distal mucosa is nearly normal in sprue (23), total methionine carriers in the longer perfused segment of such patients might be greater than in the normal subject and could account for the increased distal absorpton. Cortisol absorption in the distal small gut in sprue may also be greater than normal (12). Decreased motility and retrograde flow would also explain increased cortisol absorption. For cortisol, the increase in segment length would provide increased surface area for diffusion.

Absorption rates of the most proximal segments (75-80 cm) were frequently lower than slightly more distal studies (Fig. 1:6, 12, 25, 50 mmoles/ liter in R. L.; 25, 50 mmoles/liter in B. J.). Although we have noted this same phenomenon in cortisol and glucose absorption studies (12), we are not certain of its significance. A definite depression of absorption was seen in this zone when there was entry of gastric contents, as was detected by the fall in sample $\mathrm{pH}$ to below 6.0. Such samples were excluded from this investigation, but the absorption-decreasing effect may have been present without a $\mathrm{pH}$ change.

\section{ACKNOWLEDGMENTS}

We thank the Iowa State Board of Control and administration of Iowa State Penitentiary for making available control subjects used in this study. Mr. Donald White programmed the data from these studies for digital computer analysis.

This work was supported in part by grants AM-02534 and 1-T1 AM 5390 from the National Institute of Arthritis and Metabolic Disease and a research grant from the Upjohn Company. Subjects were hospitalized in the Metabolic Ward of the Department of Medicine or in the NIH supported Multicategorical Clinical Research Center of the State University of Iowa Hospitals, FR-59. Dr. Schedl did initial work during tenure of a Lederle Medical Faculty Award. 


\section{REFERENCES}

1. Christensen, H. N. 1962. Biological Transport. W. A. Benjamin, Inc., New York. 54.

2. Oxender, D. L., and H. N. Christensen. 1963. Distinct mediating systems for the transport of neutral amino acids by the Ehrlich cell. J. Biol. Chem. 238: 3686.

3. Inui, Y., and H. N. Christensen. 1966. Discrimination of single transport systems: the $\mathrm{Na}^{+}$-sensitive transport of neutral amino acids in the Ehrlich cell. J. Gen. Physiol. 50: 203.

4. Wilson, T. H. Intestinal Absorption. W. B. Saunders Co., Philadelphia. 110.

5. Newey, H., and D. H. Smyth. 1964. The transfer system for neutral amino acids in the rat small intestine. J. Physiol. (London). 170: 328.

6. Harper, H. A., and K. Uyeyama. 1948. Plasma methionine after oral administration of DL-methionine in human subjects. Proc. Soc. Exptl. Biol. Med. 68: 296.

7. Kuroda, Y., and N. S. Gimbel. 1954. Selective disappearance of stereoisomers of amino acids from the human small intestine. J. Appl. Physiol. 7: 148.

8. Cummins, A. J. 1952. Absorption of glucose and methionine from the human intestine; the influence of the glucose concentration in the blood and in the intestinal lumen. J. Clin. Invest. 31: 928.

9. Fleshler, B., J. H. Butt, and J. D. Wismar. 1966. Absorption of glycine and L-alanine by the human jejunum. J. Clin. Invest. 45: 1433.

10. Adibi, S. A., and S. J. Gray. 1967. Intestinal absorption of essential amino acids in man. Gastroenterology. 52: 837.

11. Blankenhorn, D. H., J. Hirsch, and E. H. Ahrens, Jr. 1955. Transintestinal intubation technic for measurement of gut length and physiologic sampling at known loci. Proc. Soc. Exptl. Biol. Med. 88: 356.

12. Schedl, H. P., and J. A. Clifton, 1963. Cortisol absorption in man. Gastroenterology. 44: 134.
13. Clifton, J. A., and H. P. Schedl. 1963. Transintestinal intubation: a method for studying the kinetics of intestinal absorption in man. In Proceedings of the 2nd World Congress of Gastroenterology, Munich, Germany. E. Schmid, J. Tomenius, and G. Watkinson, editors. S. Karger, Basel. 2: 717.

14. Schanker, L. S., D. J. Tocco, B. B. Brodie, and C. A. M. Hogben. 1958. Absorption of drugs from the rat small intestine. J. Pharmacol. Exptl. Thcrap. 123: 81.

15. Horn, M. J., D. B. Jones, and A. E. Blum. 1946. Colorimetric determination of methionine in proteins and foods. J. Biol. Chem. 166: 313.

16. Allen, W. M. 1950. A simple method for analyzing complicated absorption curves, of use in the colorimetric determination of urinary steroids. J. Clin. Endocrinol. Mctab. 10: 71 .

17. Hyden, S. 1956. A turbidometric method for the determination of higher polyethylene glycols in biological materials. Kgl. Lantbruks-Hogskol. Ann. 22: 139.

18. Lineweaver, H., and D. Burk. 1934. The determination of enzyme dissociation constants. J. Am. Chem. Soc. 56: 658 .

19. Nasset, E. S., and J. S. Ju. 1961. Mixture of endogenous and exogenous protein in the alimentary tract. J. Nutr. 74: 461.

20. Christensen, H. N., B. H. Feldman, and A. B. Hastings. 1963. Concentrative and reversible character of intestinal amino acid transport. Am. J. Physiol. 205: 255.

21. Jervis, E. L., and D. H. Smyth. 1959. The effect of concentrations of amino acids on their rate of absorption from the intestine. J. Physiol. (London). 149: 433.

22. Ingelfinger, F. J., and R. E. Moss. 1943. The motility of the small intestine in sprue. J. Clin. Invest. 22: 345.

23. Rubin, C. E.. L. L. Brandborg, A. L. Flick, P. Phelps, C. Parmentier, and S. van Niel. 1962. Studies of celiac sprue III. The effect of repeated wheat instillation into the proximal ileum of patients on a gluten-free dict. Gastrocnterology. 43: 621. 